\title{
S809 Kanat Profili Etrafındaki Sınır Tabaka Akışının Emme Tekniği ile Aktif Kontrolünün Sayısal İncelenmesi
}

\author{
Gurbet Çankaya ${ }^{1}$, Onur Erkan ${ }^{2}$, Musa Özkan ${ }^{3 *}$
}

Geliş / Received: $30 / 04 / 2020$

Revize / Revised: 18/06/2020

Kabul / Accepted: 18/06/2020

\section{$\overline{\mathbf{O Z Z}}$}

Bu çalışmada, sınır tabaka akışı aktif kontrol yöntemlerinden biri olan, sınır tabakadan kanat içerisine hava emilmesi prensibine dayanan emme tekniği kullanılarak bir rüzgar türbini kanadının aerodinamik performansının arttırılması hedeflenmiştir. Emme işlemi daimi bir jet vasıtasıyla gerçekleştirilmiş, kanat modeli olarak rüzgar türbini uygulamalarında yaygın olarak kullanılan S809 kanat profili tercih edilmiştir. Çalışma parametreleri olarak, üç ayrı jet konumu $\left(\mathrm{L}_{\mathrm{jet}}=0.1 \mathrm{c}, 0.26 \mathrm{c}, 0.36 \mathrm{c}\right)$ ve üç ayrı jet oranı $\left(\mathrm{R}_{\mathrm{jet}}=0.1,0.3,0.5\right)$ seçilmiştir. Emme jeti genişliği sabit olup veter uzunluğunun \%2.5'i kadar ve emme jeti açısı $\left(\theta_{\text {jet }}\right)$ bölgesel jet yüzeyine $90^{\circ}$ olacak şekilde ayarlanmıştır. İki boyutlu türbülanslı akış için sayısal analiz; $\alpha=15^{\circ}$ hücum açısında ve $\operatorname{Re}=10^{6}$ 'da SST k- $\omega$ türbülans modeli kullanılarak gerçekleştirilmiştir. İlk olarak emme jeti konumunun etkisi, ardından en iyi sonucu veren emme jeti konumu seçilerek emme jeti oranının etkisi araştırılmıştır. Kanat profili etrafındaki akışa ait simülasyon sonuçları incelendiğinde, en iyi sonuç emme jeti konumu $0.36 \mathrm{c}$ (Jet-3) ve emme jeti oranı 0.5 olduğunda alınmıştır. Jet kullanılmadığı duruma göre $C_{L} / C_{D}$ oranı 17.92 'den 273.03 'e yükselmiştir. Emme jeti ile kontrol yönteminin uygulanması ile kontrolsüz duruma göre $\mathrm{Cl}$ değeri yaklaşık olarak 1.211'den 1.8'e yükselmiş, Cd değeri ise 0.068 'den 0.0066 'ya düşmüştür.

Anahtar Kelimeler - Aktif kontrol yöntemi, Emme jeti, S809 kanat profili, Sınır tabaka akışı 


\title{
Numerical Investigation of Active Control of Boundary Layer Flow Around S809 Airfoil with Suction Method
}

\begin{abstract}
In this study, it is aimed to increase the aerodynamic performance of a wind turbine blade by using the suction technique which is one of the active control methods of boundary layer flows based on the principle of air intake from the boundary layer into the blade. Suction is defined as a continuous jet and the S809 airfoil is preferred which is widely used in wind turbine applications as a blade model. Three different jet positions (Ljet $=0.1 \mathrm{c}$, $0.26 \mathrm{c}, 0.36 \mathrm{c})$ and three different jet ratios $\left(\mathrm{R}_{\mathrm{jet}}=0.1,0.3,0.5\right)$ are selected as study parameters. The suction jet width is fixed and is $2.5 \%$ of chord length and the suction jet angle $\left(\theta_{\text {jet }}\right)$ is $90^{\circ}$ to the local jet surface. Numerical analysis for a two-dimensional turbulent flow is performed using SST k- $\omega$ turbulence model with an angle of attack of $\alpha=15^{\circ}$ and $\operatorname{Re}=10^{6}$. Firstly, the effect of the suction jet position is investigated and then the effect of the suction jet ratio is examined with an optimum suction jet position that showed the best result. When the simulation results of the flow around the airfoil are examined, the best result is obtained when the suction jet position is jet-3 $(0.36 \mathrm{c})$ and the suction jet ratio is $0.5 . \mathrm{C}_{\mathrm{L}} / \mathrm{C}_{\mathrm{D}}$ ratio is increased from 17.92 to 273.03 compared to the no-jet situation. By the application of the suction jet control method, the $\mathrm{C}_{\mathrm{L}}$ is increased approximately from 1.211 to 1.8 and the $\mathrm{C}_{\mathrm{D}}$ is decreased from 0.068 to 0.0066 in comparison to the uncontrolled case.
\end{abstract}

Keywords - Active control method, Boundary layer flow, S809 airfoil, Suction jet 


\section{GíRİ̧}

Dünya'da giderek artan enerji tüketiminde, fosil kaynakların yetersizliği ve atmosferi kirletmesi gibi bir durum söz konusu iken enerjinin doğal ve yenilenebilir enerji kaynaklarından elde edilmesi çok önem kazanmıştır. Bu hususta dikkat çeken bir enerji kaynağı olan rüzgar enerjisi dünya genelinde önemli bir paya sahip olmuştur. Rüzgardan elektrik enerjisi üretmek için yapılan rüzgar türbinleri geniş bir alanda kullanılmıştır. Rüzgar türbinlerinde hava akışını yönlendiren ve enerjinin elde edilmesinde kritik bir konumda olan türbin kanatlarının aerodinamik performanslarının artırılması günümüze değin sıklıkla araştırılmıştır. Kanat profili etrafında oluşan sınır tabaka akışının kontrol edilebilmesi ise bu çalışmaların asıl amacını oluşturmuştur.

Sınır tabaka akışı kontrol yöntemleri, pasif ve aktif akış kontrol yöntemleri olarak iki gruba ayrılır. Pasif akış kontrol yönteminde yardımcı güç ve kontrol döngüsü gerekmezken aktif akış kontrol yönteminde ise enerji harcanması gerekir. Pasif akış kontrolü, Microtab ve Gurney Flap gibi yapısal aygıtlar ile sağlanabilmektedir. Ancak, bu aygıtlar rüzgar türbini kanadının boyutu arttıkça yapısal ve yorulma yüklenmesine neden olabilmektedirler. Bu noktada sınır tabaka akışının kontrolünde aktif kontrol yöntemleri ciddi bir çalışma alanı oluşturmuştur. Örneğin, akış kontrol yöntemi olarak sürekli jet gibi aktif kontrol metotlarının kullanımı avantaj sağlamaktadır [1,2].

Hassan [3], \%12 kalınlığında VR-7 helikopter kanadının aerodinamiğini geliştirmek için bir emme ve üfleme jetinin eş zamanlı kullanımına dayanan yeni hibrit bir Aktif Akış Kontrolü (AAK) stratejisini değerlendirmek üzere sayısal bir çalışma yapmıştır. Mach sayısının 0.3 olduğu serbest akış için mevcut hibrit AAK kullanımının aerodinamik faydalar sağladığı görülmüştür. Bu yöntemle sağlanan ana faydalardan birisi olan kanat profili üzerinden ayrılmış sınır tabakanın kısmen yeniden bağlanabilmesinin darbeli emme jetinin kullanılmasıyla, uygun bir basınç gradyanı için, ayrılmış akış bölgesi ardındaki girdapların parçalanmasının ise darbeli üfleme jetinin kullanılmasıyla elde edildiği bildirilmiştir. Genç ve Kaynak [4], üfleme veya emme kullanarak NACA 2415 kanat profili üzerinde laminer ayrılma kabarcığının meydana geldiği akışın kontrolünü hesaplamalı olarak araştırmışlardır. Türbülanslı akışa geçiş bölgesinde olan $2 \times 10^{5}$ Reynolds sayısında ve $\alpha=8^{\circ}$, de, veter uzunluğunun $\% 2.5$ genişliğindeki tek bir jeti, kanatların üst yüzeyine yerleştirmişlerdir. Jet konumları, jet hızı oranları ve jet açıları gibi çeşitli parametreler ile yapmış oldukları yaklaşık 200 sayısal simülasyonu incelemişlerdir. Sonuçlar emme hızı oranının en büyük değerinde nispeten küçcuk emme hızı oranlarına göre akışa daha iyi etki ettiğini, daha düşük üfleme hızı oranının ise daha yüksek üfleme hızı oranlarına kıyasla akışa daha olumlu etki yaptığını göstermiştir. Liu vd. [5], kanat profilinin sürüklenmesini azaltmak için hücum kenarında emme ve kuyruk kenarında üfleme yapan bir emme-üfleme birleşik kontrol tekniği geliştirmişlerdir. Çözümler, düzeltilmiş Wilcox k- $\omega$ geçiş modelinin [6] emmeye bağlı geçiş konumunu en doğru şekilde tahmin ettiğini göstermiştir. Kanallar boyunca havanın kütlesel debisinin etkisini, kanal genişliğini, aralığını ve boyutunu tartışmışlardır. Ayrıca sayısal sonuçlar, emme-üfleme kontrolünün sadece emme ile karşılaştırıldığında daha düşük sürükleme sağladığını göstermiştir. Pehlivanoğlu vd. [7], aerodinamik performansı artırmak için bir kanattan geçen transonik akışa uyguladıkları kontrolü optimize etmişlerdir. Kontrolü, kanat yüzeyinde emme veya üfleme kullanarak uygulamışlardır. Çalışmada, emme/üfleme portunun yeri ve açısı ile bu porttaki kütlesel debi gibi değişkenleri incelemişlerdir. Optimizasyon ile aerodinamik performans \%20'nin üzerinde artmıştır. Goodarzi vd. [8] aktif akış kontrolünü, NACA 0015 kanat profilinin üst yüzeyine yerleştirilen, veter uzunluğunun $\% 2.5$ genişliğindeki bir üfleme jetini kullanarak Re $=4.55 \times 10^{5}$ 'te $12^{\circ}$ ile $17^{\circ}$ aralığındaki 6 farklı hücum açısında araştırmışlardır. Jet konumu, jet hızı oranı ve jet açısı parametrelerini araştırmışlardır. Simülasyon sonuçları, üflemenin kaldırma miktarını artıracağını ve sürüklemeyi azaltacağını göstermiştir. Ayrıca yüksek hücum açılarında, üfleme ayrılmayı geciktirmiş ve kanat profilinin performansını artırmıştır. Kang ve Park [2], akış kontrol cihazı ile donatılmış bir rüzgar türbini kanadının aerodinamik performansını, Ansys Fluent kullanarak incelemiş̧tir. Hesaplama için Delft Teknik Üniversitesi'nde düşük türbülanslı rüzgar tünelinde testleri yapılan S809 kanat profilini kullanmışlardır. Hücum açısının değişmesi ile birlikte, S809 kanat profili için kararlı durum sonuçlarını deneysel sonuçlarla karşılaş̧ırmışlar ve sonuçlar birbirleriyle iyi bir uyum göstermiştir. Jet yuvasının konumunu $\mathrm{x} / \mathrm{c}=0.6$ olarak belirlediklerinde sonuçlar $\alpha=14.24^{\circ}$ 'de maksimum kaldırma katsayısını vermiştir. Jet yuvasının konumunu $\mathrm{x} / \mathrm{c}=0.025$ olarak belirlediklerinde ise, sonuçlar $\alpha=14.24^{\circ}$ ve $20.15^{\circ}$ 'te akış ayrılmasının geciktirildiğini göstermiş̧ir. Yousefi vd. [1] ise araştırmalarında, bir NACA 0012 kanat profili üzerindeki sayısal akış kontrolünü sağlamak için emme işleminin etkisini değerlendirmişlerdir. Akış türünü, tamamen türbülanslı $\left(\mathrm{Re}=5 \times 10^{5}\right)$ ve türbülans modelini Menter'in kayma gerilmesi taşınım (Shear-Stress-Transport) [9] modeli olarak belirlemişlerdir. Kanat profili üzerindeki emme işlemini, üniform ve standart (dikey emme) kabul etmişlerdir. 
Sonuçlar, emme hızı oranı arttıkça kaldırma katsayısının arttığını ve sürükleme katsayısının azaldığını göstermiştir. Kaldırma-sürükleme oranındaki maksimum artış, emme hızı oranı 0.5 olduğunda sağlanmıştır. Ayrıca, emme jetinin genişliği artırıldığında kaldırma-sürükleme oranı yükselmiş ve veter uzunluğunun \%2.5'inde maksimum değerine ulaşmıştır. Azim vd. [10] NACA 4412 kanat profili için veter uzunluğunun \%2'si genişliğindeki bir kanalı 5 farklı konuma yerleştirmişler ve kanallardaki emme basınçlarının sonuçlarını incelemişlerdir. Daha düşük basınçlı emmenin, sınır tabaka ayrılmasını kuyruk kenarına doğru hareket ettirerek akış ayrılmasını geciktirdiği sonucuna varmışlardır. Kanat profilinin üst yüzeyinde veter uzunluğunun \%68'inde 65 kPa'lık emme basıncı kullanılmasıyla, 13 hücum açısı ve 0.6 Ma sayısı koşullarında türbülanslı akışa geçişin veter uzunluğunun \%91'ine kadar geciktirilmesinin mümkün olduğu bildirilmiştir. Buna bağlı olarak laminer akış bölgesi uzamış ve kaldırma kuvveti artmıştır. Ayrıca, düşük hücum açısında, emme sonrası kaldırma-sürükleme oranı da akış kontrolünün yapılmadığı duruma kıyasla yaklaşık 2.24 kat artmıştır. Shi ve vd. [11] Hibrit Laminer Akış Kontrolü’nü (HLAK), $0.5 \mathrm{~mm}$ ile $7 \mathrm{~mm}$ aralığındaki emme deliği genişlikleri için sayısal olarak incelemişlerdir. Çalışmada emme katsayısının, emme deliği genişliğinin ve pozisyonunun etkisini analiz etmişlerdir. Tek delikli simülasyon sonuçları; emme katsayısını doğru bir şekilde arttırmanın ve delik konumunu kuyruk kenarına uygun bir konuma yerleştirmenin sürüklemeyi azaltmak ve türbülansa geçişi geciktirmek için kullanılabileceğini göstermiştir. Çalışmada ek olarak üç delikli emme kontrolü de irdelenmiştir. Üç delikli tasarımı optimize etmek için modifiye Radyal Temel Fonkiyonu (RTF) sinir ağını ve modifiye diferansiyel gelişim algoritmasını kullanmışlardır. Tasarım değişkenleri olarak emme katsayısı, delik genişliği, delik konumu ve delik aralığı seçilmiştir. Optimizasyondan sonra türbülansa geçişin $\% 17$ oranında geciktirilebildiği ve sürükleme katsayısının \%12.1 oranında azaltılabildiği görülmüştür.

Mevcut çalışmada, aktif kontrol yöntemlerinden biri olan sınır tabakadan hava emilmesi prensibine dayanan emme tekniği kullanılarak türbin kanatlarının aerodinamik performansının artırılması hedeflenmiştir. Çalışmada kanat modeli olarak rüzgar türbini uygulamalarında yaygın olarak kullanılan S809 kanat profili tercih edilmiştir. Literatürdeki çalışmalarda S809 kanat profili, özellikle tüm hücum açılarında diğer kanat profillerine kıyasla daha yüksek kaldırma katsayısı sağlaması gibi avantajları olduğundan sıklıkla kullanılmıştır [12]. Ayrıca literatürde, kanat profili üzerindeki sınır tabaka akışının emme tekniği ile aktif kontrolünde S809 kanat profiline ait bir araştırmanın mevcut olmayışı da bu çalışmanın motivasyonunu artırmıştır.

\section{MATERYAL VE METOT}

\section{A. Numerik Model ve Ayrılaştırma}

Çalışmada analiz edilen S809 kanat profili ve etrafındaki hesaplama alanı Şekil 1'deki gibi oluşturulmuştur. Kanat geometrisinin oluşturulmasında kullanılan noktaların koordinatları Airfoil Tools [13] isimli kanat profili veri tabanından alınmıştır. Kanat 2 boyutlu ve $2 \mathrm{~m}$ veter uzunluğunda oluşturulmuş ve hesaplama bölgesi veter uzunluğu ile orantılı bir şekilde meydana getirilmiştir. Hesaplama bölgesindeki yarım dairenin yarıçapı veter uzunluğunun 12.5 katı (12.5c), dikdörtgen yüksekliği veter uzunluğunun 25 katı (25c) ve dikdörtgen uzunluğu veterin 20 katı (20c) olarak modellenmiştir.

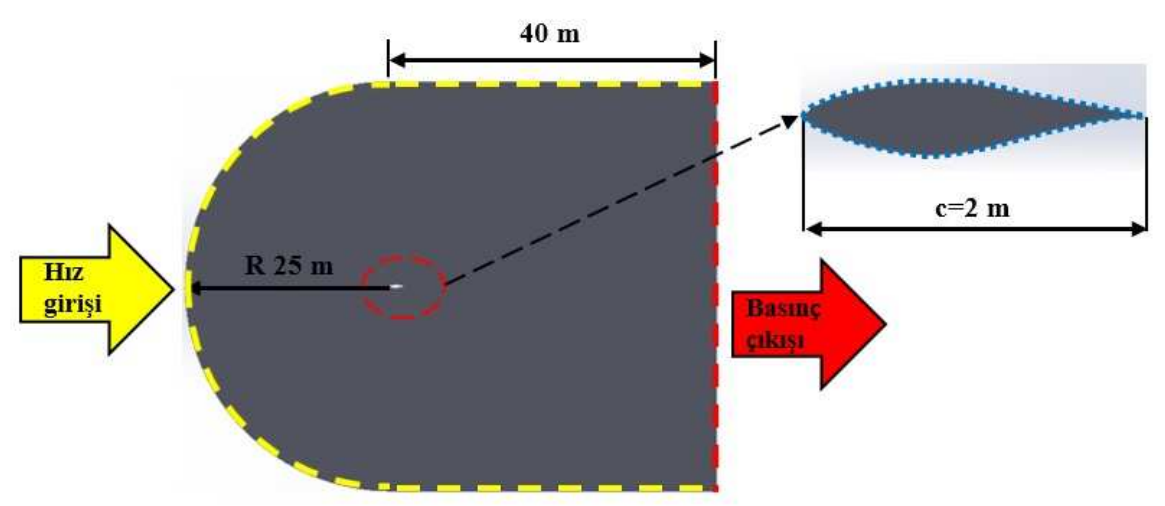

Şekil 1. Sayısal model ve sınır koşulları 
Numerik analizlerin yapılacağı geometri oluşturulduktan sonra Reynolds-Ortalamalı Navier Stokes ve türbülans modelinden gelen ek taşınım denklemlerinin sayısal olarak çözümlenebilmesi için hesaplama bölgesinin ayrıklaştırılmasına geçilmiştir. Ayrıklaştırma işlemi literatürde yapılandırılmamış (unstructured) olarak adlandırılan ve Şekil 2'de verildiği gibi çoğunlukla üçgensel elemanlar içeren bir ağ yapısı ile gerçekleştirilmiştir. Ağ yapısı oluşturma işlemi iteratif bir süreç olarak ele alınmıştır. Oluşturulan ağ yapısının analiz sonuçlarını etkilememesi gerektiğinden ağ bağımsızlık testleri yapılmıştır. Ağ bağımsızlık testine sonraki bölümlerde detaylı olarak değinilmiştir. Testlerin sonucunda Şekil 2'de gösterilen ağ yapısının kullanılmasına karar verilmiştir. Bu ağ yapısı elde edilirken göz önüne alınan bir diğer husus da boyutsuz duvar uzaklığı $\left(\mathrm{y}^{+}\right)$değeridir. Bahsedilen $\mathrm{y}^{+}$ değerinin iyi bir sınır tabaka çözümlemesi yapılabilmesi için 1 ile 5 arasında olması gerektiğinden kanat yüzeyi üzerindeki ilk ağ tabakasının kalınlığı $\mathrm{y}^{+}$değerinin bahsi geçen değerler arasında kalmasını sağlayacak şekilde oluşturulmuştur. Kullanılması kararlaştırılan ağ yapısının genel özellikleri maksimum çarpıklık 0.84, ortalama enboy oranı 5.3, diklik kalitesi ortalama 0.96 olarak belirlenmiştir.

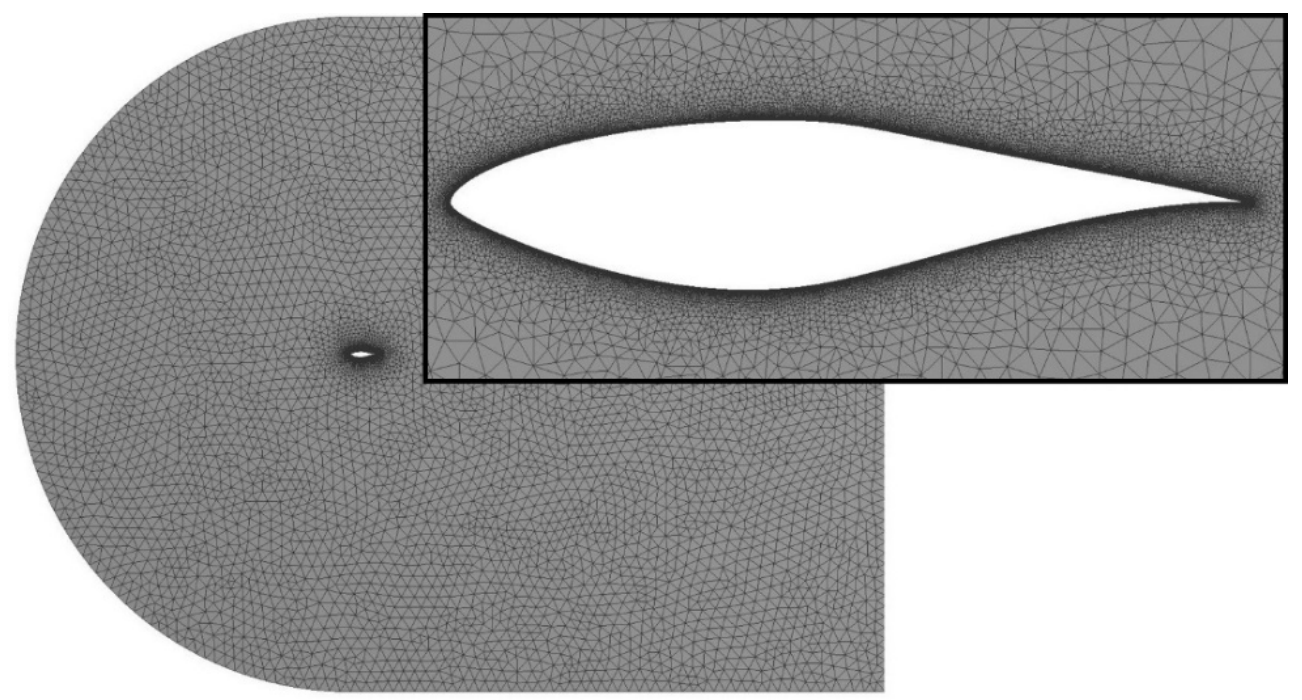

Şekil 2. Ă̆ yapısı

\section{B. Sınır Koşulları}

Çalışmada ayrıklaştırma işlemi de gerçekleştirildikten sonra çözümleme yapılmasına geçilmiştir. Numerik modelde kullanılan sınır koşulları Şekil 1'de de gösterildiği gibi; serbest hava akış hızı girişi, basınç çıkışına ek olarak kanat yüzeyinde kaymama sınır koşulu ve jet deliğinde ise vakumun sağlanması için hız girişi olarak tanımlanmıştır. Serbest hava akış hızı $7.15 \mathrm{~m} / \mathrm{s}$ olarak belirlenmiş, böylece hava yoğunluğunun $1.246 \mathrm{~kg} / \mathrm{m}^{3}$, dinamik viskozitenin $1.778 \times 10^{-5} \mathrm{~kg} / \mathrm{m}$.s olduğu şartlarda $2 \mathrm{~m}$ veter uzunluğu için Reynolds sayısının $10^{6}$ olması sağlanmıştır. Ayrıca serbest akış hava hızı kanada $15^{\circ}$ hücum açısıyla gelecek şekilde oluşturulmuştur. Hesaplama alanında basınç çıkışı olarak adlandırılan bölgeye atmosferik basınç sınır koşulu verilmiştir. Kanat yüzeyi etrafındaki akış özellikleri; 2 boyutlu, sıkıştırılamaz, sürekli, türbülanslı ve viskoz olarak tanımlanmıştır. Analizlerde aerodinamik uygulamalarında sıklıkla başvurulan ve sınır tabaka ayrılmasının gözlendiği akışları çözümlemede oldukça başarılı iki denklemli SST k- $\omega$ türbülans modeli kullanılmıştır [14,15]. Bu türbülans modeli, viskoz sınır tabakayı çözümlemek için k- $\omega$ ve duvardan uzak bölgeleri hesaplamak için ise k- $\varepsilon$ modelini kullanan hibrit bir türbülans modeli olduğundan tercih edilmiştir [16].

Çalışmada daha önce bahsedilen emme sınır koşulu Şekil 3'te şematik olarak gösterilmiştir. Emme jeti uygulamasında kullanılan parametreler Tablo 1'de verildiği gibi sınır koşulu olarak uygulanmıştır. 


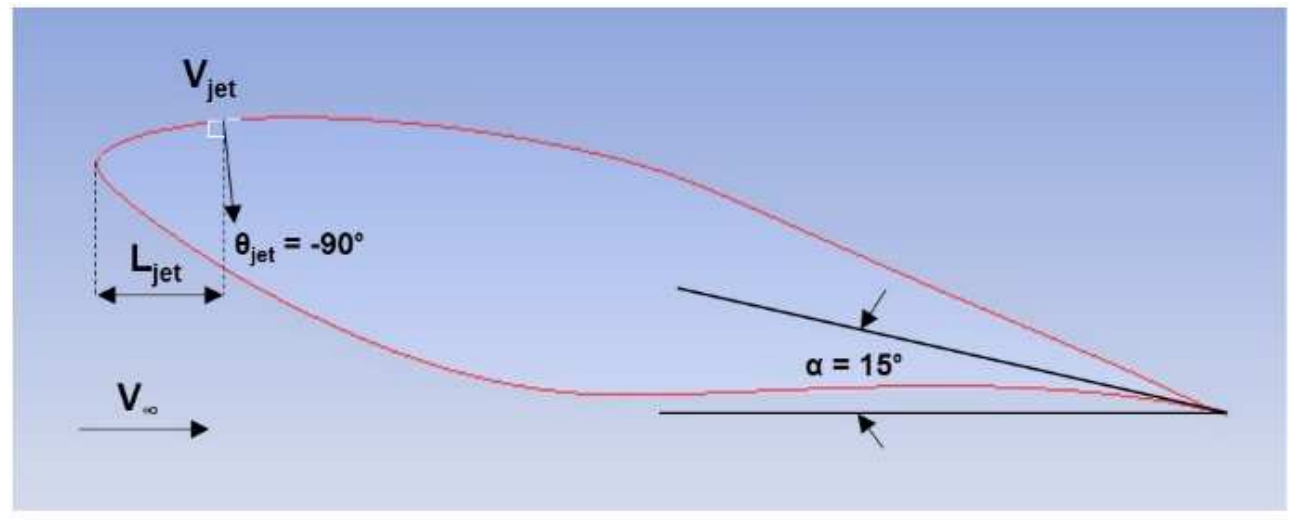

Şekil 3. Emme jeti uygulanmasının şematik olarak gösterilmesi

Tablo 1. Emme jeti parametreleri

\begin{tabular}{|c|c|c|c|c|c|c|c|c|c|}
\hline \multicolumn{10}{|c|}{ Emme jeti genişliği $=\% 2.5 \mathrm{c}$} \\
\hline Jet konumu ( $\left.\mathbf{L}_{\text {jet }}\right)$ & \multicolumn{3}{|c|}{ Jet $-1=0.1 \mathrm{c}$} & \multicolumn{3}{|c|}{ Jet- $2=0.26 \mathrm{c}$} & \multicolumn{3}{|c|}{ Jet- $3=0.36 c$} \\
\hline Jet hiz oranı $\left(\mathbf{R}_{\text {jet }}\right)$ & 0.1 & 0.3 & 0.5 & 0.1 & 0.3 & 0.5 & 0.1 & 0.3 & 0.5 \\
\hline Jet $\operatorname{açısı~}\left(\theta_{\text {jet }}\right)$ & & $-90^{\circ}$ & & & $-90^{\circ}$ & & & $-90^{\circ}$ & \\
\hline
\end{tabular}

Analizler 3 ayrı jet konumu ve 3 ayrı emme jeti oranında gerçekleştirilmiştir. Emme jetleri sırasıyla veter uzunluğunun $0.1,0.26$ ve 0.36 katı mesafesinde ve kanat profilinin üst yüzeyinde konumlandırılmıştır. Şekil 3 'te gösterilen $\theta_{\text {jet }}$ açısı bölgesel jet yüzeyine dik ve yüzeyden içeriye olacak şekilde ( $\left.-90^{\circ}\right)$ uygulanmıştır. Bu çalışmada emme jeti açısı ve emme jeti genişliği sabit tutularak emme jeti konumu ve emme jeti oranının etkisine ait sonuçlar ortaya konulmuştur. Emme jeti oranı $\left(R_{\text {jet }}\right)$ boyutsuzlaştırma yapmak adına jet hızının serbest akış hızına oranı $\left(R_{\text {jet }}\right.$ $\left.=\mathrm{V}_{\text {jet }} / \mathrm{V}_{\infty}\right)$ şeklinde ifade edilmiştir.

\section{BULGULAR VE TARTIȘMA}

\section{A. A g Yapısı Denetimi}

Sayısal çalışmada kullanılacak modelin ağ yapısından etkilenmemesi gerekir. Diğer bir deyişle analiz sonuçlarının ayrıklaştırma işleminden kaynaklı herhangi bir hata içermemesi çalışmanın güvenilirliği açısından önemlidir. Bu sebeple mevcut çalışma sonuçlarının ağ yapısından etkilenmediği ayrıklaştırma modelini bulma adına ă̆ bağımsızlık testi gerçekleştirilmiştir. Testler $15^{\circ}$ hücum açısında yapılmıştır. Ağ yapılarına göre denetlenen sonuçlar kaldırma ve sürükleme katsayıları olarak tercih edilmiştir. Bu sonuçların eleman sayısına göre değişimlerinin verildiği Şekil 4'te de görüldüğü gibi ağ elemanı sayısı yaklaşık 150000'e ulaştıktan sonra sonuçlarda değişme gözlenmemiştir. Buradan yola çıkarak 154207 eleman sayısına sahip ağ yapısının kullanılmasına karar verilmiştir. 


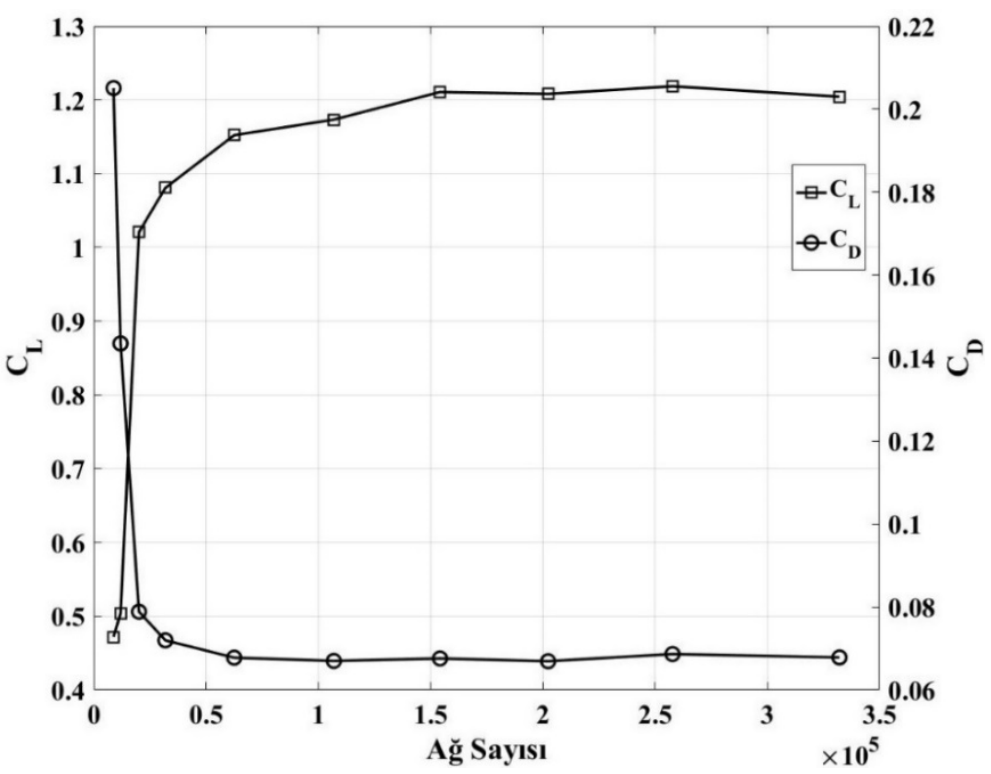

Şekil 4. A $\breve{g}$ bağımsızlık testi

\section{B. Sonuçların Doğrulanması}

Araştırılan numerik modelin ağ yapısından bağımsız olduğuna karar verildikten sonra oluşturulan numerik modelin doğru bir şekilde çalışıp çalışmadığı denetlenmiştir. Doğrulama işlemi, jet ile akış kontrolünün yapılmadığı durum için $15^{\circ}$ hücum açısı ve $10^{6}$ Reynolds sayısı şartlarında elde edilen sonuçların aynı şartlarda Ramsay vd. [17] tarafından gerçekleştirilen deneylerin sonuçlarıyla kıyaslanmasıyla gerçekleştirilmiştir. Yapılan karşılaştırma sonucunda Şekil 5'te verildiği gibi numerik modelin deneysel veriler ile tutarlı olduğu görülmüştür. Oluşturulan sayısal modelin uygunluğu da denetlendikten sonra emme jeti uygulamalarına geçilmiştir.

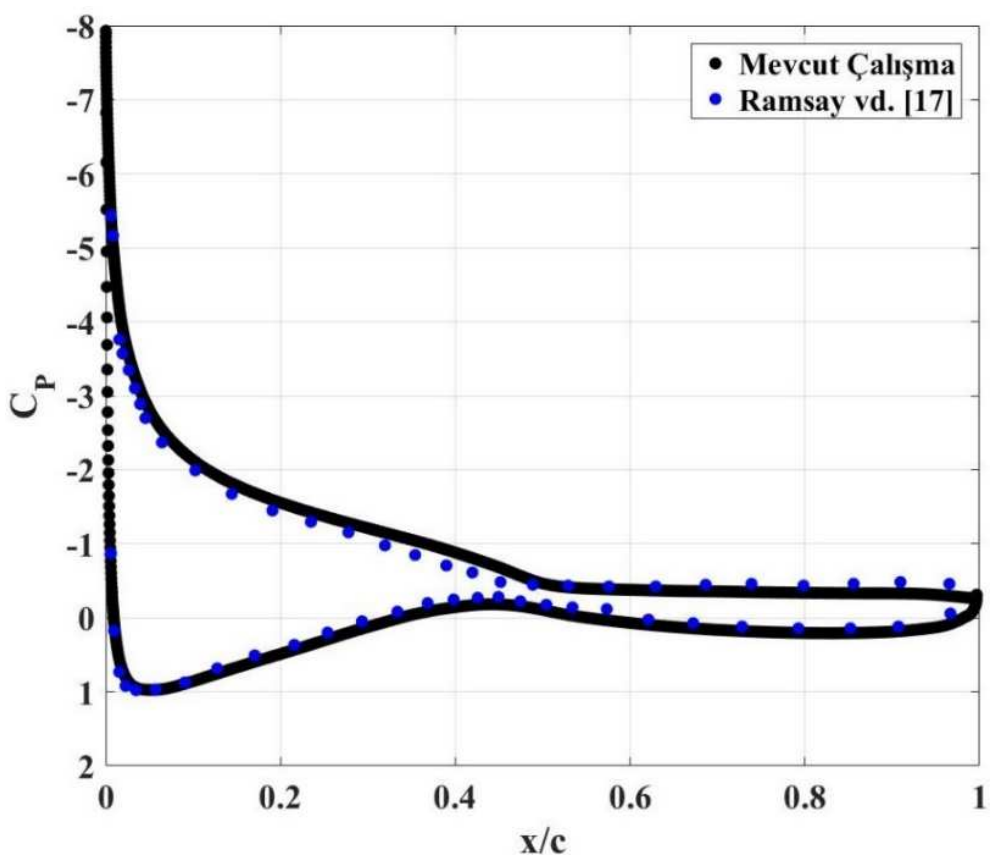

Şekil 5. Mevcut çalışmanın basınç katsayısı değerlerinin Ramsay vd. [17] tarafından raporlanan deneysel veriler ile karşılaştırılması 


\section{Emme Jeti Konumunun Etkisi}

Çalışmada öncelikle emme jetinin kanat üzerinde nerede daha iyi sonuç vereceğini bulmak için konum araştırması yapılmıştır. Emme jeti açısı bölgesel emme jeti yüzeyine $\theta_{\text {jet }}=-90^{\circ}$ ve emme jeti oranı $R_{\text {jet }}=0.1$ değerindeyken jet konumunun etkisi incelenmiştir. Jet konumu hücum kenarından kuyruk kenarına doğru yer değiştirdikçe sürükleme katsayısı değeri Şekil 6'daki gibi azalış, kaldırma katsayısı ise artış göstermiştir. Jetin konumunun nerede olduğu fark etmeksizin emme jetinin Şekil 7'deki $C_{L} / C_{D}$ oranlarından da anlaşıldığı gibi kanat aerodinamik performansına olumlu etki yaptığı görülmekle beraber en faydalı konumun 0.36c (Jet-3) olduğu sonucuna varılmıştır. Akış kontrolü yapılmaması halinde oluşan akım çizgilerine bakıldığında Şekil 8'de akışın kanat yüzeyinden büyük bir ayrılma kabarcığı ile koptuğu görülmüştür. Emme ile akış kontrolü yapıldığında ise ayrılma kabarcığının giderek küçüldüğü ve Jet-3 için en küçük boyuta ulaştığı gözlemlenmiştir.
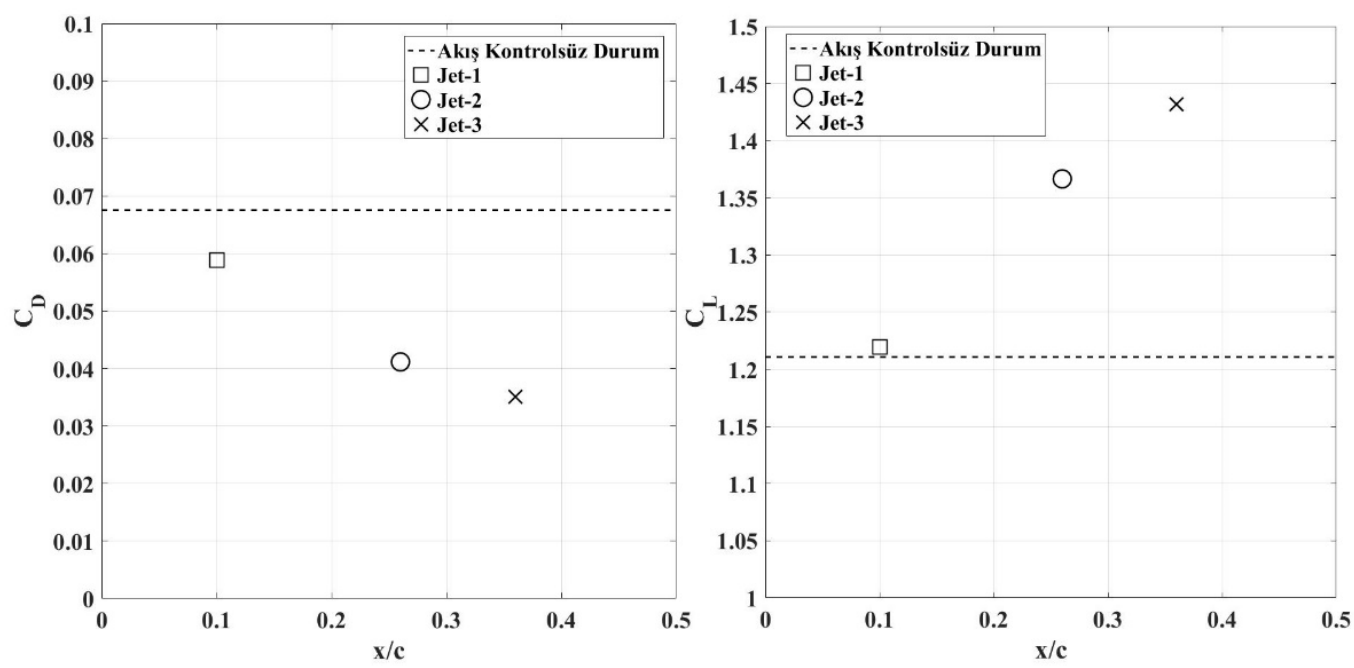

Şekil 6. Üç ayrı emme jeti konumu ve akış kontrolsüz durum için sürükleme $\left(C_{D}\right)$ ve kaldırma $\left(C_{L}\right)$ katsayısı değerleri

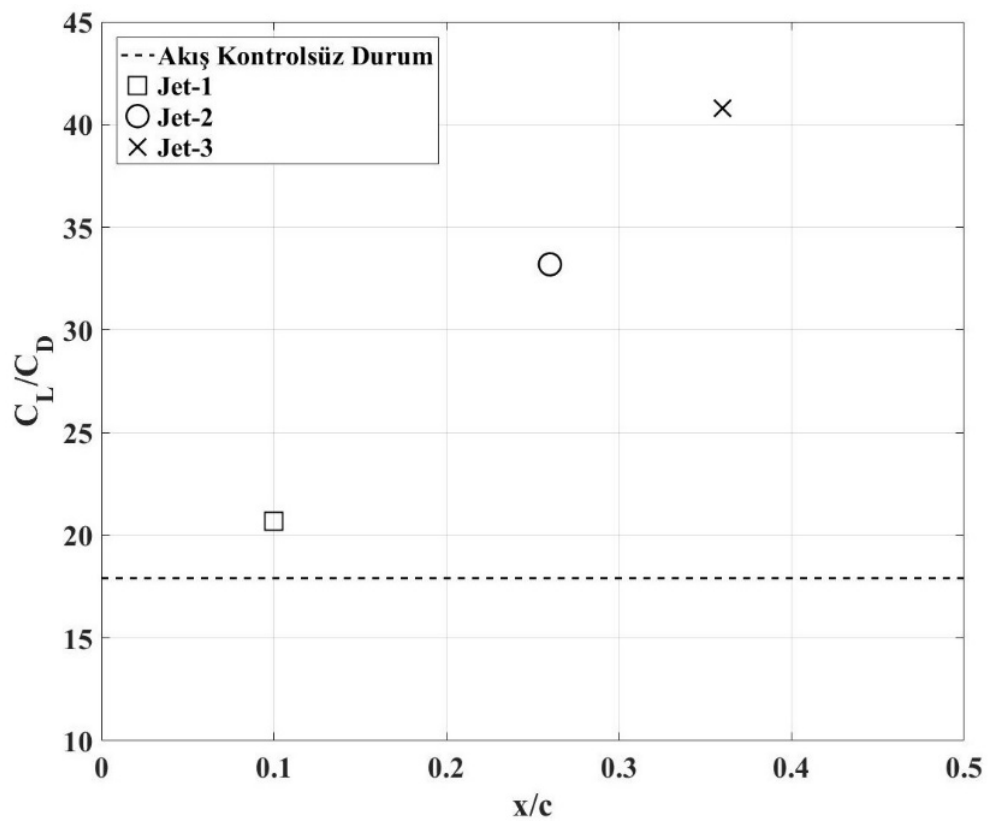

Şekil 7. Üç ayrı emme jeti konumu ve akış kontrolsüz durum için $C_{L} / C_{D}$ oranları 


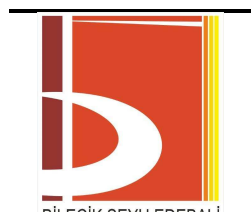

BŞEÜ Fen Bilimleri Dergisi

7(1), 461-472, 2020

BSEU Journal of Science

DOI: $10.35193 /$ bseufbd.729822

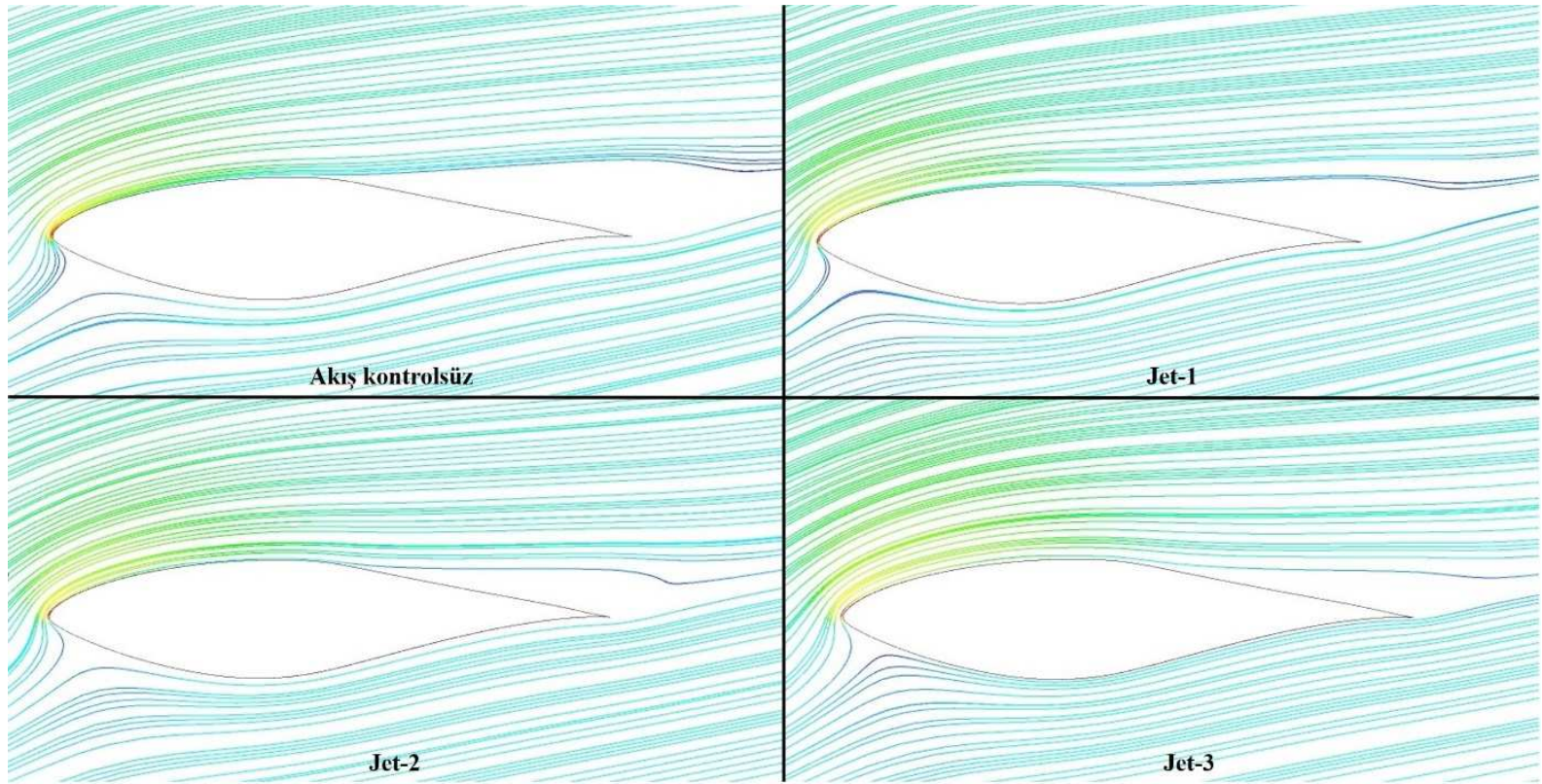

Şekil 8. Üç ayrı jet konumu ve akış kontrolsüz durum için kanat profili etrafındaki akım çizgileri

\section{Emme Jeti Oranının Etkisi}

En iyi emme jeti konumu 0.36c (Jet-3) olarak belirlendikten sonra emme jeti oranının $\left(\mathrm{R}_{\mathrm{jet}}\right)$ etkisi araştırılmıştır. Emme jeti oranı $0.1,0.3$ ve 0.5 olarak yapılan sayısal analiz sonucunda jet oranı arttıkça $C_{D}$ değeri Şekil 9'daki gibi azalış gösterirken, $C_{L}$ değeri ise artış göstermiştir. Sürükleme ve kaldırma katsayısı değerleri en iyi jet oranı olan $R_{\text {jet }}=0.5$ için $C_{D}=0.00659$ ve $C_{L}=1.7982$ olarak elde edilmiştir. Akış kontrolünün olmadığı duruma kıyasla $C_{L} / C_{D}$ oranları da Şekil 10'daki gibi artış göstermiştir.
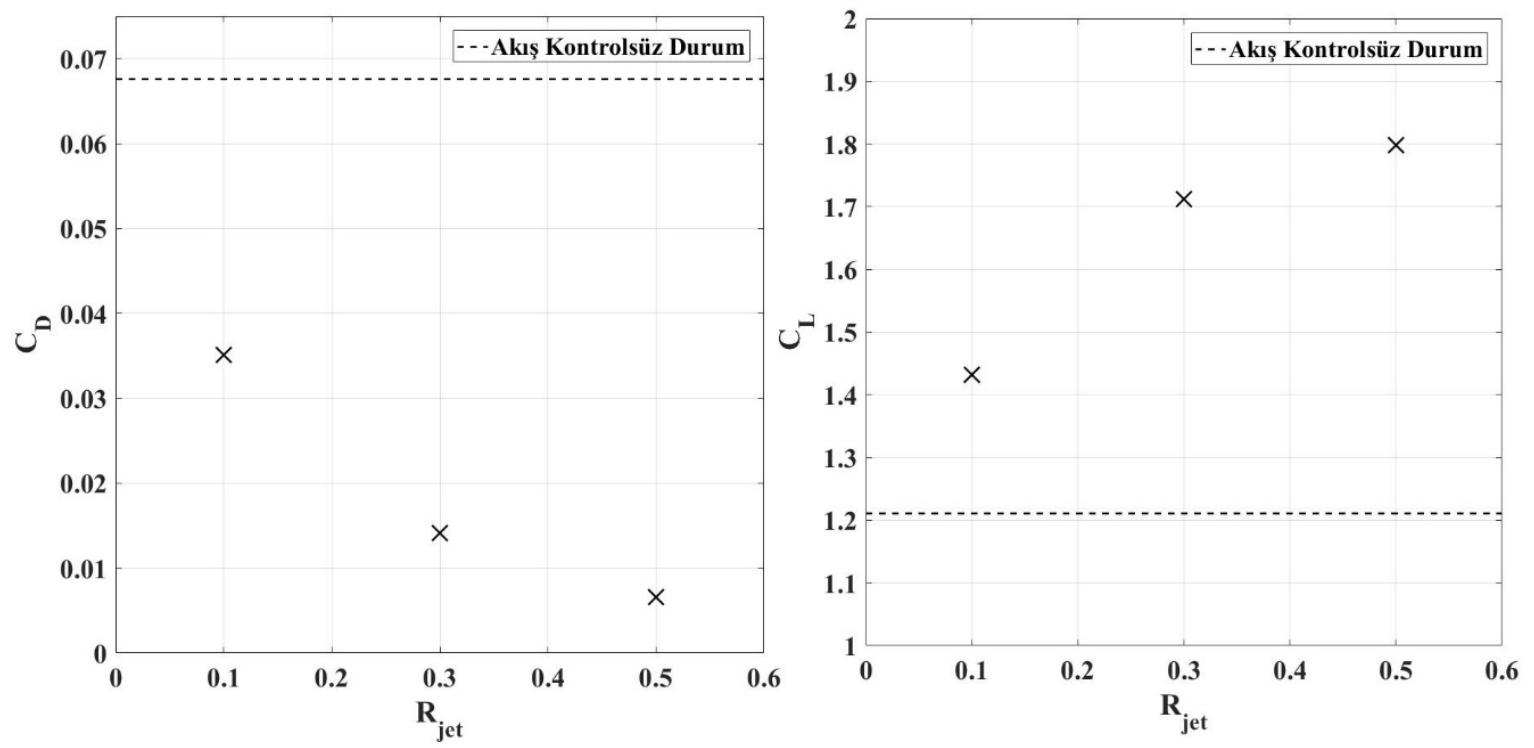

Şekil 9. Üç ayrı emme jeti oranı ve akış kontrolsüz durum için sürükleme $\left(C_{D}\right)$ ve kaldırma $\left(C_{L}\right)$ katsayısı değerleri 


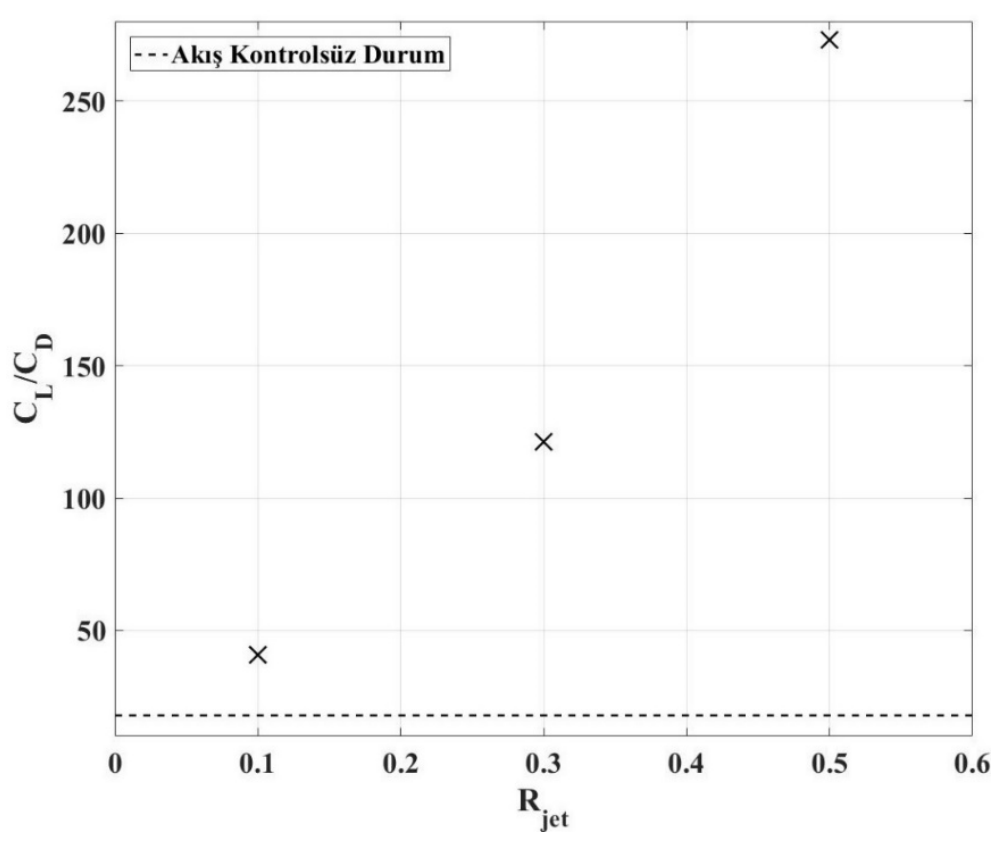

Şekil 10. Üç ayrı emme jeti oranı ve akış kontrolsüz durum için $C_{L} / C_{D}$ oranları

Jet konumu 0.36 c olarak ayarlandığında, jet oranının 0.1 olması halinde akış kontrolünün yapılmadığı duruma göre ayrılma kabarcığında ciddi bir azalma meydana geldiği Şekil 11'de görülmektedir. Jet oranının artmasıyla ayrılma kabarcığı da giderek küçülmüş ve $R_{\text {jet }}=0.3$ için akış ayrılması önlenebilmiştir.

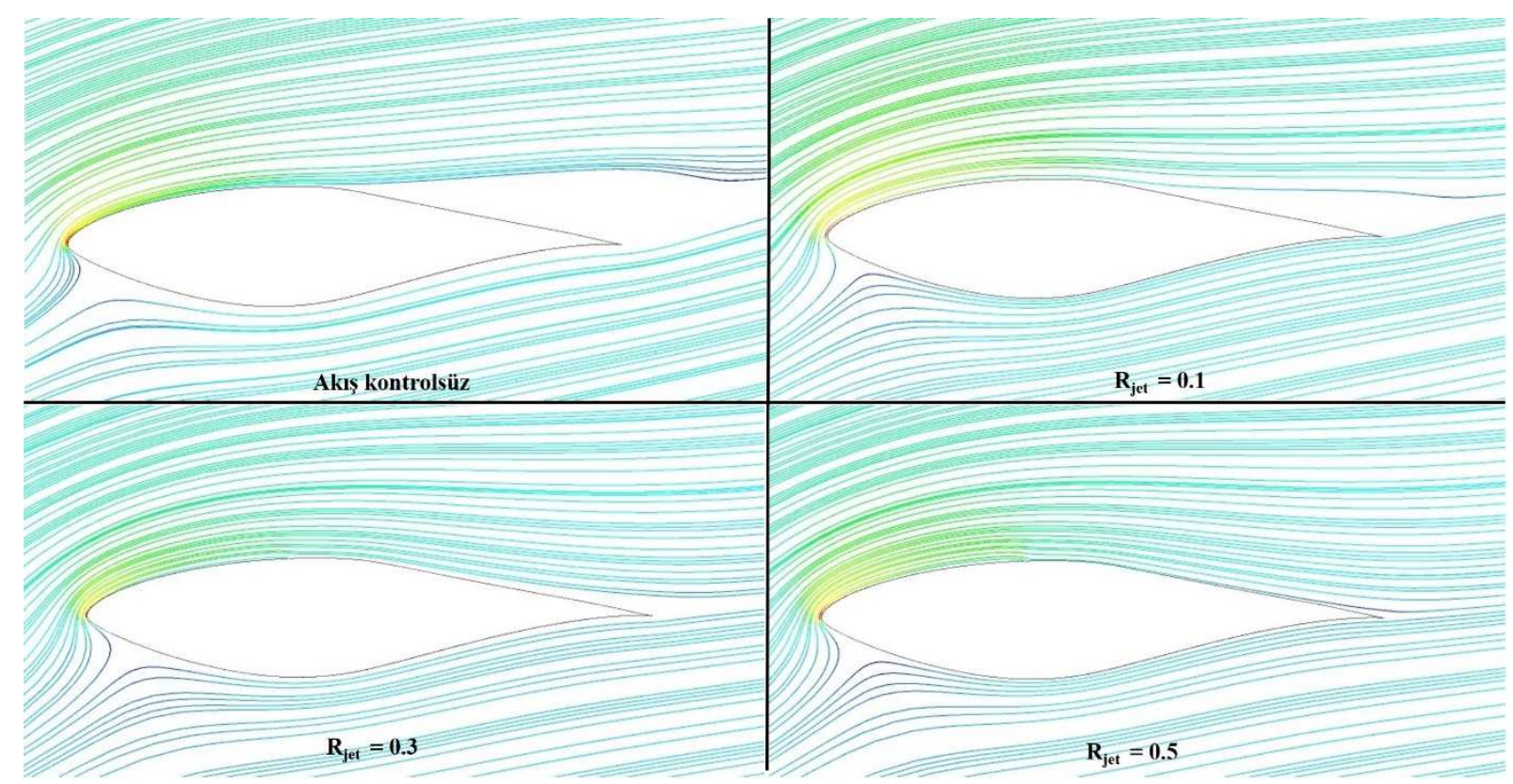

Şekil 11. Üç ayrı jet oranı ve akış kontrolsüz durum için kanat profili etrafındaki akım çizgileri 


\section{SONUÇLAR}

Bu çalışmada, $15^{\circ}$ lik hücum açısında, $10^{6}$ Reynolds sayısında ve iki boyutlu türbülanslı bir akıştaki sınır tabaka akışının, emme jeti uygulaması ile aktif olarak kontrolü sayısal olarak incelenmiştir. Kanat modeli olarak S809 kanat profili tercih edilmiştir. Çalışma sabit jet genişliği ve açısında, üç ayrı jet konumu $\left(\mathrm{L}_{\mathrm{jet}}=0.1 \mathrm{c}, 0.26 \mathrm{c}\right.$, $0.36 \mathrm{c})$ ve üç ayrı jet oranı $\left(\mathrm{R}_{\mathrm{jet}}=0.1,0.3,0.5\right)$ için gerçekleştirilmiştir. SST k- $\omega$ türbülans modeli kullanılarak gerçekleştirilen sayısal analizlerden aktif akış kontrolü için kullanılacak emme jetinin kanat üst yüzeyinde $0.36 \mathrm{c}$ 'de konumlandırılması halinde, ayrılma kabarcığının küçültülerek daha yüksek kaldırma ve daha düşük sürüklemenin oluştuğu görülmüştür. Optimum jet konumunda emme oranı araştırıldığında ise, kanadın aerodinamik performansına en iyi etkinin $\mathrm{R}_{\text {jet }}=0.5$ 'te elde edildiği sonucuna varılmıştır. Bu durumda kaldırma katsayısı 1.8 'e kadar yükselirken sürükleme katsayısı 0.066 ' ya kadar düşmüş dolayısıyla $C_{L} / C_{D}$ oranı 273'e kadar artmıştır.

\section{KAYNAKLAR}

[1] Yousefi, K., Saleh, S. R., \& Zahedi, P. (2013). Numerical investigation of suction and length of suction jet on aerodynamic characteristics of the NACA 0012 airfoil. International Journal of Materials, Mechanics and Manufacturing, 1(2), 136-142.

[2] Kang, T. J., \& Park, W. G. (2013). Numerical investigation of active control for an S809 wind turbine airfoil. International Journal of Precision Engineering and Manufacturing, 14(6), 1037-1041.

[3] Hassan, A. (2006). A two-point active flow control strategy for improved airfoil stall/post-stall aerodynamics. In 44th AIAA Aerospace Sciences Meeting and Exhibit (p. 99).

[4] Genç, M. S., \& Kaynak, Ü. (2009). Control of laminar separation bubble over a NACA2415 aerofoil at low re transitional flow using blowing/suction. In International Conference on Aerospace Sciences and Aviation Technology (Vol. 13, No. Aerospace Sciences and Aviation Technology, ASAT-13, May 26-28, 2009, pp. 1-17). The Military Technical College.

[5] Liu, P. Q., Duan, H. S., Chen, J. Z., \& He, Y. W. (2010). Numerical study of suction-blowing flow control technology for an airfoil. Journal of aircraft, 47(1), 229-239.

[6] Wilcox, D.C. (2004). Turbulence modelling for CFD, 2nd Edition, DCW Industries, Inc., ISBN 1-928729$10-\mathrm{X}$.

[7] Pehlivanoğlu, Y. V., Yağız, B., Kandil, O., \& Baysal, O. (2010). Particle swarm optimization of suction and blowing on airfoils at transonic speeds. Journal of aircraft, 47(6), 1955-1965.

[8] Goodarzi, M., Rahimi, M., \& Fereidouni, R. (2012). Investigation of active flow control over NACA0015 airfoil via blowing. International Journal of Aerospace Sciences, 1(4), 57-63.

[9] Menter, F.R. (1994). Two-equation eddy-viscosity turbulence models for engineering applications. AIAA Journal, 32(8), 1598-1605.

[10] Azim, R., Hasan, M. M., \& Ali, M. (2015). Numerical investigation on the delay of boundary layer separation by suction for NACA 4412. Procedia Engineering, 105, 329-334.

[11] Shi, Y., Bai, J., Hua, J., \& Yang, T. (2015). Numerical analysis and optimization of boundary layer suction on airfoils. Chinese Journal of Aeronautics, 28(2), 357-367.

[12] Douvi, E. C., \& Margaris, D. P. (2012). Aerodynamic Characteristics of S809 vs. NACA 0012 Airfoil for Wind Turbine Applications. In Proceedings of the 5th International Conference from Scientific Computing to Computational Engineering, 5th IC-SCCE, Athens Greece, 4-7 July.

[13] Airfoil Tools, http://airfoiltools.com/airfoil/details?airfoil=s809-nr, (23.04.2020). 
[14] Erkan, O. \& Özkan, M. (2020). Investigation of the flow over NACA 63-415 airfoil. Black Sea Journal of Engineering and Science, 3(2), 50-56.

[15] Özkan, M., Thomas, P. J., Cooper, A. J., \& Garrett, S. J. (2016). Comparison of the effects of surface roughness and confinement on rotor-stator cavity flow. Engineering Applications of Computational Fluid Mechanics, 11(1), 142-158.

[16] Langtry, R.B., \& Menter, F.R. (2009). Correlation-based transition modeling for unstructured parallelized computational fluid dynamics codes. AIAA Journal, 47(12), 2894-2906.

[17] Ramsay, R. F., Hoffman, M. J., \& Gregorek, G. M. (1995). Effects of grit roughness and pitch oscillations on the S809 airfoil (No. NREL/TP-442-7817). National Renewable Energy Lab., Golden, CO (United States). 